\title{
Тува в диалоге культур: компаративистский контекст
}

\author{
Юрий В. Попков \\ Институт философии и права Сибирского отделения Российской академии наук, Российская Федерация, \\ Евгений А. Тюгашев \\ Новосибирский национальный исследовательский государственный университет, Российская Федерация
}

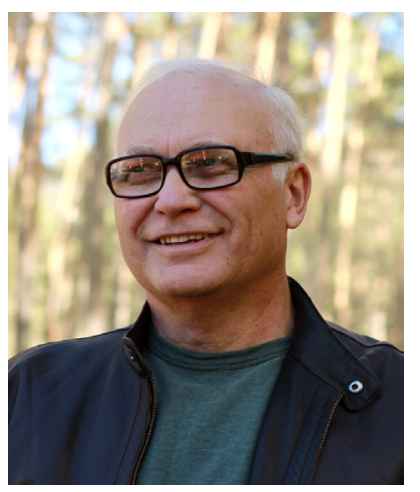

В статье актуализируется проблема диалога культур в мировом и региональном аспекте и решается значимая для сравнительного тувиноведения задача по диагностике позиционирования Тувы в диалоге культур в компаративистском контексте. Культуру авторы трактуют как отдельный социальный организм в его конкретно-исторической специфике (по О. Шпенглеру). Именно в рамках такого представления корректно говорить о способности культуры вступать в диалог и его вести.

О диалоге культур правомерно вести речь только в том случае, когда осуществляется содержательный и конструктивный речевой информационный взаимообмен. Для этого культура должна быть говорящей, не-молчащей культурой и обладать способностью не кмонологу, а диалогу. В рамках разговорного формата диалога культура призвана быть субъектно-ориентированной. Ее должна интересовать и привлекать субъектность чужой культуры в ее самоценности.

Проведенный компаративный анализ положения традиционной тувинской культуры

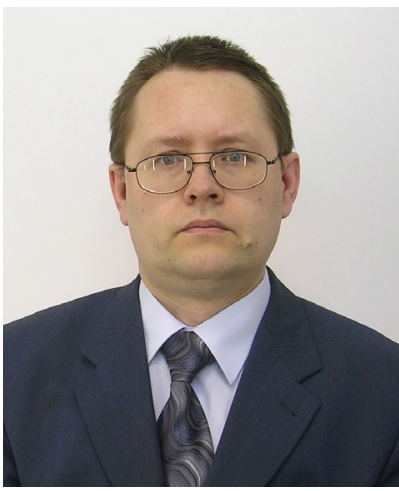
дает основание для следующих заключений: по критерию открытости к диалогу она относится к категории сравнительно закрытых культур; по критерию избирательности в диалоге тувинцев можно охарактеризовать как преимущественно азиатско-ориентированных; в рамках сопоставления культур «говорящих» $и$ «молчащих» тувинская культура больше соответствует культуре молчания; в горизонте диалоговых и монологовых культур ее можно оценить как в большей степени монологичную.

Распространение современных глобализационных сетей и циифровизация публичной и повседневной жизни способствуют переформатированию положения Тувы в диалоге культур. Одновременно с этим, по мнению авторов, актуальными для тувинцев является культивирование уважительного и заинтересованного отношения к собственной культуре, ее более глубокое познание.

Ключевые слова: Тува; тувинская культура; диалог культур; межкультурный диалог; межкультурная коммуникация; межкультурные взаимодействия; урянхайский вопрос; тувинский вопрос

Для циитирования:

Попков Ю. В., Тюгашев Е. А. Тува в диалоге культур: компаративистский контекст // Новые исследования Тувы. 2020, № 4. C. 217-229. DOI: www.doi.org/10.25178/nit.2020.4.15

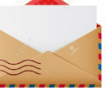

Попков Юрий Владимирович - доктор философских наук, профессор, главный научный сотрудник отдела социальных и правовых исследований Института философии и права Сибирского отделения Российской академии наук. Адрес: 630090, Россия, г. Новосибирск, ул. Николаева, д. 8. Тел.: +7 (383) 330-22-40. Эл. адрес: yuripopkov54@mail.ru

Тюгашев Евгений Александрович - доктор философских наук, доцент кафедры теории и истории государства и права Института философии и права Новосибирского национального исследовательского государственного университета. Адрес: 630090, Россия, г. Новосибирск, ул. Пирогова, д. 1. Тел.: +7 (383) 363-42-54. Эл. адрес: filosof10@yandex.ru

POРКОV, Yuri Vladimirovich, Doctor of Philosophy, Professor; Chief Researcher, Department of Social and Legal Studies, Institute of Philosophy and Law, Siberian Branch, Russian Academy of Sciences. Postal address: 8 Nikolaev St., 630090 Novosibirsk, Russian Federation. Tel.: +7 (383) 330-22-40. E-mail: yuripopkov54@mail.ru ORCID ID: 0000-0002-1036-9253

TYUGASHEV, Evgeny Alexandrovich, Doctor of Philosophy, Associate professor, Department of Theory and History of Law, Institute of Philosophy and Law, Novosibirsk National Research State University. Postal address: 1 Pirogov St., 630090 Novosibirsk, Russian Federation. Tel.: +7 (383) 269-42-54. E-mail: filosof10@yandex.ru ORCID ID: 0000-0001-6217-0601 


\title{
Tuva in the cultural dialogue: a comparative context
}

Article

\author{
Yurii V. Popkov \\ Institute of Philosophy and Law, Siberian Branch of the Russian Academy of Sciences, Russian Federation, \\ Evgenii A. Tyugashev \\ Novosibirsk State University, Russian Federation
}

\begin{abstract}
The article brings up the problem of cultural dialogue problem in global and regional aspects and focuses on the issue topical for comparative Tuvan studies - the one of positioning Tuva in the cultural dialogue within a compara-tive context. According to $O$. Spengler, culture can be seen as a separate social system in its specific historical peculiarity. This very concept allows us to dis-cuss the culture's ability of culture to enter and conduct a dialogue.

We have reason to speak about the dialogue of cultures only if there is a meaningful and constructive exchange of speech and information going on. To engage in this, a culture has to be a speaking and non-silent one, and have the ability to speak not in monologues, but in dialogues. In its colloquial form, the culture has to be subject-oriented, attracted by the subjectness of another cul-ture in its unique objective value.

The comparative analysis of the situation traditional Tuvan culture finds itself in leads us to a number of conclusions. Firstly, by the criterion of open-ness to dialogue, it can be classified as a relatively closed culture. By the crite-rion of dialogue selectivity, Tuvans can be characterized as predominantly Asian-oriented; on the scale between "speaking" and "silent" cultures, Tuvan culture tends to be seen as silent, and it can be referred to as more monologue-like than dialogue-like.

The current spread of contemporary networks and digitalization of public and personal life contribute to the changes in Tuva's position in the cultural di-alogue. At the same time, we believe that Tuvans will only benefit from cultivat-ing a respectful and keen attitude to their own culture and from a better under-standing of its details.
\end{abstract}

Keywords: Tuva; Tuvan culture; cultural dialogue; cross-cultural dia-logue; cross-cultural communication; cross-cultural interaction; Uryankhai is-sue; Tuvan issue

For citation:

Popkov Yu. V. and Tyugashev E. A. Tuva v dialoge kul'tur: komparativistskii kontekst [Tuva in the cultural dialogue: a comparative context]. New Research of Tuva, 2020, no. 4, pp. 217-229. (In Russ.). DOI: www.doi.org/10.25178/nit.2020.4.15

\section{Введение}

Известно, что во многих отношениях Тува принадлежит к уникальным регионам России, начиная от ее глубинного внутриконтинентального расположения, в значительной степени окаймляемого горными системами, при отсутствии железнодорожного сообения с любым другим регионом России или иных стран, заканчивая этнической структурой населения, в которой абсолютное большинство составляют представители титульного народа. В силу особенностей своего географического положения и сложности исторической судьбы Тува не имела непосредственных межкультурных контактов со многими другими народами. Межкультурный диалог - это открытый обмен мнениями между представителями различных культур, основанный на взаимоуважении и понимании друг друга ${ }^{1}$. Очевидно, что по сравнению с другими странами Тува обладает небольшим опытом диалога с различными культурами мира (Ламажаа, 2018: 134). Если со своими соседями - монголами, китайцами и русскими - хозяйственные и культурные отношения на протяжении нескольких столетий поддерживались, хотя и с разной степенью интенсивности и глубины, более или менее регулярно (Монгуш, 2008), то

${ }^{1}$ White paper on intercultural dialogue: «Living together as equals in dignity». Strasbourg: Council of Europe [Электронный ресурс] // Council of Europe. 2008. URL: http://www.coe.int/t/dg4/intercultural/source/white\%20paper_final_revised_en.pdf (дата обращения: 26.09.2020.) 
в отношениях с отдаленным и дальним зарубежьем в недавней истории наблюдалось, можно сказать, «молчание Тувы» (Маадыр, 2018: 25). В советский период ее культурная изоляция в данном отношении только иногда прорывалась (Адыгбай, 2012: Электр. ресурс).

В связи с этим для тувиноведения представляет интерес решаемая в настоящей статье задача анализа места Тувы в диалоге культур. Трудности ее позиции и перспективы развития диалоговых отношений рассматриваются в компаративистском контексте, то есть путем сравнения тувинской культуры с другими культурами. Наряду с этим решаются две другие задачи: характеристика проблемы диалога культур в региональном и мировом контексте; выявление эвристического потенциала понятия диалога культур и использование его для анализа позиционирования тувинской культуры.

В понимании культуры мы исходим не из ее наиболее популярной сегодня информационно-семиотической концепции (Тхагапсоев и др., 2020), а из восходящей к О. Шпенглеру трактовки культуры как отдельного социального организма в его конкретно-исторической специфике (Тюгашев, 2019). Культуры в качестве макросоциальных субъектов способны вступать в диалог как на массовом уровне, так и в лице специализированных групп - трансляторов культуры (Ларченко, Еремин, 1991: 65-66). Именно в рамках такого представления корректно говорить о культуре как, во-первых, собственно субъекте, во-вторых, субъекте (акторе) диалога.

\section{Проблема диалога культур в региональном и мировом контексте}

Ситуации контактов Тувы с окружающим миром в общественно-политическом и геополитическом дискурсах сегодня все чаще интерпретируются в парадигме диалога. В этих контактах действительно происходит обмен мнениями, достижениями, накопленным историческим опытом, предложениями по развитию взаимоотношений регионов - и сходных, и различающихся по своему социокультурному потенциалу. Безусловно, такие контакты выступают предпосылкой развития. Так, характеризуя вхождение Тувинской Народной Республики в состав СССР, Ш. В. Кара-оол говорит о том, что оно основывалось на длительном знакомстве с русским народом, на понимании его ментальности и характера ${ }^{1}$ Конкретные возможности для сотрудничества в области культуры усматриваются во взаимодействии Республики Тыва с Республикой Хакасия, например, в рамках сопряженного проведения международного фестиваля живой музыки и веры «Устуу-Хурээ» и фестиваля «Мир Сибири»². В качестве конкретных площадок для обмена опытом, для межкультурного диалога рассматриваются Центр тувинской традиционной культуры и ремесел, Центр русской культуры ${ }^{3}$.

Диалоговые ситуации требуют определенной организации, позволяющей и высказаться, и выслушать собеседника. Это не всегда просто. В отношении проблемы диалога культур Л. Хертек образно замечает: «Как мне выразить себя, как понять тебя?» 4 Эта ремарка отсылает к стихотворению Ф. И. Тютчева «Silentium!», в котором говорится о выборе молчания, отказа от диалога из-за возможного взаимонепонимания.

Но такой отказ возможен только в качестве временной паузы. Иначе не избежать конфронтации. Применительно к общественно-политической жизни Республики Тыва ее руководство большое значение придает умению вести диалог как с федеральным центром, так и с различными категориями населения ${ }^{5}$.

\footnotetext{
${ }^{1}$ Диалог Тувы и Приморья - от большой политики до семейных ценностей [Электронный ресурс] // Ежедневные Новости Владивостока: сетевое издание. 2015. 23 нояб. URL: https://novostivl.ru/msg/20804.htm (дата обращения: 20.09.2020).

${ }^{2}$ Диалог губернаторов-соседей: Шолбан Кара-оол (Тува) и Валентин Коновалов (Хакасия) договорились сотрудничать [Электронный ресурс] // MK в Тыве: сетевое издание. 2019. 1 июля. URL: https://www.mk-tuva.ru/ politics/2019/07/01/dialog-gubernatorovsosedey-sholban-karaool-tuva-i-valentin-konovalov-khakasiya-dogovorilissotrudnichat.html (дата обращения: 20.09.2020).

${ }^{3}$ В Туве открылся Центр тувинской традиционной культуры и ремесел [Электронный ресурс] // Тува.Азия: портал тувиноведения. 2012. 2 марта. URL: https://www.tuva.asia/news/tuva/4518-otkrytie.html (дата обращения: 26.09.2020).

${ }^{4}$ Хертек Л. Как мне выразить себя, как понять тебя? [Электронный ресурс] // Тува.Азия: портал тувиноведения. 2010. 9 октября. URL: https://www.tuva.asia/news/ tuva/2380-hertek.html (дата обращения: 20.09.2020).

${ }^{5}$ Премьер Шолбан Кара-оол провел открытый диалог с учителями русского языка [Электронный ресурс] // Официальный портал Республики Тыва. 2016. 27 мая. URL: http://gov.tuva.ru/press_center/news/education/24486/ (дата обращения: 20.09.2020); Шолбан Кара-оол: Спасибо тоджинцам за откровенное обсуждение наболевших вопросов, диалог и поддержку [Электронный ресурс] // Партия «Единая Россия»: федеральный сайт. 2016.
} 
Если коммуникативная ситуация все же объективно сложилась, то диалог так или иначе начнется или возобновится. Поэтому в современном мире значительное внимание стало уделяться проблеме диалога культур, сталкивающихся в различных взаимодействиях.

С образованием в 1992 г. Европейского союза, в который вошли 27 государств, возникла задача его интеграции, в связи с чем Совет Европы в 2000-е годы выдвинул серию инициатив по межкультурному диалогу в различных его измерениях ${ }^{1}$. В интерпретации Совета Европы межкультурный диалог способствует интеграции многокультурных обществ. Он предполагает готовность и способность выражать себя и прислушиваться к мнению других, основывается на ценностях свободы и равенства, человеческого достоинства и прав человека, демократической гражданственности.

Данная интерпретация межкультурного диалога была оценена неоднозначно. Ряд исследователей охарактеризовали ее как продукт колониального дискурса, унифицирующего культурные различия (Cliche, Wiesand, 2009; Igbino, 2011; Aman, 2012).

ЮНЕСКО поддерживает идею диалога между культурами в перспективе сохранения культурного разнообразия в условиях глобализацииㄹㄹ . Во всемирном докладе ЮНЕСКО № 2 «Инвестирование в культурное разнообразие и диалог между культурами» подчеркнута потребность в разработке новых подходов к межкультурному диалогу, учитывающих соотносительность культур, наличие у них общих элементов и совместных целей, а также перспективу изменения конфигураций существующих точек зрения и пониманий мира ${ }^{3}$.

Можно заметить, что ЮНЕСКО универсализирует понимание диалога культур, рассматривая его как феномен всемирной истории. Совет Европы, в отличие от ЮНЕСКО, рассматривает диалог культур как возможность, реализуемую в парадигме ценностей новоевропейской цивилизации. Следовательно, возникает вопрос об общем понятии диалога культур и роли этого феномена в судьбе отдельных стран и народов.

С учетом неоднозначности в трактовке диалога культур, прежде чем обратиться к анализу данной проблемы применительно к Туве, остановимся на ряде концептуально значимых вопросов рассмотрения феномена диалога культур.

\section{Концептуально-проблемные вопросы диалога культур}

Диалог культур справедливо воспринимается как довольно неопределенная метафора, не отличающая по своему содержанию от понятий взаимодействия культур, межкультурного общения и межкультурной коммуникации. Так, прежде всего отмечается девальвация значения понятия «диалог», его сведение к необязывающим метафорам, публицистическим штампам (Тульчинский, 2015: 148).

Наряду с профанированием концепта в научном и общественно-политических дискурсах наблюдается и противоположная тенденция. Подчеркивается, что диалог культур сакрализуется, становится «символом веры» (Орнатская, 2014: 49). Высказывается также мнение, что диалог культур - это мифологема, скрывающая конфликтные речевые взаимодействия в формате «проповеди» и «отповеди»4.

Таким образом, возникают сомнения в когнитивной состоятельности и эвристичности данной метафоры. Энциклопедические определения диалога культур также не вносят ясность в его содержа-

14 сент. URL: https://tyva.er.ru/activity/news/sholban-kara-ool-spasibo-todzhincam-za-otkrovennoe-obsuzhdenienabolevshih-voprosov-dialog-i-podderzhku (дата обращения: 20.09.2020); Конструктивный диалог. Глава Тувы встретился с руководством компании En+Group [Электронный ресурс] // Информационное агентство «ТуваМедиаГрупп»: сетевое издание. 2019. 22 ноября. URL: https://tmgnews.ru/obshhestvo-i-chelovek/konstruktivnyjdialog-glava-tuvy-vstretilsya-s-rukovodstvom-kompanii-en-group/ (дата обращения: 20.09.2020).

${ }^{1}$ White paper on intercultural dialogue: «Living together as equals in dignity». Strasbourg: Council of Еurope [Электронный ресурс] // Council of Europe. 2008. URL: http://www.coe.int/t/dg4/intercultural/source/white\%20paper_final_revised_en.pdf (дата обращения: 26.09.2020.)

${ }^{2}$ Universal Declaration on Cultural Diversity, adopted by the 31st session of the General Conference of UNESCO, Paris, 2 November 2001. Paris: UNESCO [Электронный ресурс] // UNESCO. 2001. URL: http://www.unesco.org/new/fileadmin/MULTIMEDIA/HQ/CLT/pdf/5_Cultural_Diversity_EN.pdf (access date: 21.09.2020).

${ }^{3}$ UNESCO World Report 2: Investing in cultural diversity and intercultural dialogue. Paris: UNESCO [Электронный ресурс] // UNESCO. 2009. URL: unesdoc.unesco.org/images/0018/001852/185202E.pdf (access date: 21.09.2020).

${ }^{4}$ Каплуненко, А. М. (1999) Проповедь и отповедь как формы межкультурной коммуникации, или миф о диалоге культур [Электронный ресурс] // Иркутский государственный университет. URL: https://buk.irk.ru/library/ sbornik_99/kaplunenko_a.doc (дата обращения: 26.09.2020). 
ние. Например, М. Р. Жбанков предлагает понимать диалог культур как непосредственные отношения между культурами (Жбанков, 2001: 308). Это довольно абстрактное определение он дополняет одним существенным конкретизирующим признаком, указывая на сопутствующее преобразование систем ценностей, мировоззрения, культурных паттернов. Но при использовании этого признака остается неясным, чем же диалог культур отличается, например, от культурной ассимиляции.

Единственный диалоговый признак, на который указывает М.Р. Жбанков, - несовместимость языков культур, порождающая «семантическое землетрясение» (там же: 309). Однако это отрицательный признак, фиксирующий наличие взаимодействия между культурами при одновременном отсутствии диалога между ними. Впрочем, представляет интерес указание на существование языков культур, на которых ведется диалог. Но при этом не ясен статус языков в многоуровневой системе языковой деятельности конкретной культуры.

В «Новой философской энциклопедии», в посвященной данной проблеме статье, констатируется, что диалог культур обычно представляется как взаимодействие культур (Библер, Ахутин, 2010: 659). Излагая учение В. С. Библера о диалоге культур, авторы статьи предлагают учесть ряд аспектов в понимании существа диалога и культур. Не все эти предложения убедительны в плане методологической эвристики. Поэтому кратко прокомментируем предложения В. С. Библера и А. В. Ахутина.

Сразу оговоримся, что едва ли приемлема характеристика диалога культур как проективного понятия, описывающего не диалог эмпирически наличных конкретных культур, а диалог «возможностей бытия культурой» (там же: 660). Подобная концепция межкультурного диалога, относимого не к текущей реальности, а к идеальному миру будущего, разделяется дипломатами (Leeds-Hurwitz, 2014). На наш же взгляд, следует оговаривать различные модальности диалога культур. Так, например, те же В. С. Библер и А. В. Ахутин уверенно говорят о диалоге античной и возрожденческой культур (Библер, Ахутин, 2010: 660). Следовательно, метафора диалога культур вполне применима к исторически состоявшимся культурам.

Важным представляется указание на открытость культуры как субъекта возможного диалога (там же: 659). С учетом культурологического различения открытых и закрытых культур возможны соответствующая идентификация конкретных культур и оценка их способности к диалогу.

В. С. Библер и А. В. Ахутин полагают, что культура как произведение находится в сфере притяжения некоего архетипа - «число», «атом», «форма», «эйдос» и т. п. (там же: 660). Данный первообраз идентифицирует конкретную культуру и полифонически разыгрывается множеством ее авторов

Культуру предлагается понимать в качестве произведения-диалога, в котором участвуют автор, исполнители и аудитория. Каждая культура имеет собственное парадигмально-доминантное произведение. Для античности - это трагедия, в которой переживается катарсис. Для западноевропейского средневековья - это мистерия «в-(о)круге-храма». Возникает вопрос о том, существуют ли такие доминантные произведения в каждой национальной культуре?

Дифференцированность культуры как композиции определяет ее амбивалентность и, как следствие, неоднозначность, проблематичность самой себя. Поэтому культура вопрошает у будущего, у прошлого, у всех, кто к ней прислушивается (там же). Добавим, что существенной инструментальной функцией диалога считается снятие напряженности в отношениях (Попов, 2005: 70).

Предполагается, что каждая из культур - античная, средневековая, новоевропейская, - обладает своей логикой, собственными логическими началами (Библер, Ахутин, 2010: 660). А следовательно своими категориями? формами мышления? законами логики? Поскольку разработки в области логики культуры только разворачиваются, то перспективны и исследования логик национальных культур на различных этапах их развития.

Важно отметить, что предложивший концепт диалога культур М. М. Бахтин ассоциировал его с метафорой (Бахтин, 1979: 334-335). Слова «как бы диалог» и выражают отношение М. М. Бахтина к диалогу культур как к метафоре.

Данная метафора обеспечивает когнитивный перенос лингвистического понятия «диалог» в область культурологии. В результате при описании взаимодействия культур мы ориентируемся на выделение собственно диалога как формы взаимодействия. А это обязывает исследователя к привлечению тех дисциплинарных разделов лингвистики, которые изучают феномен диалога.

В языкознании диалогическая речь определяется как первичная, естественная форма речи, состоящая из обмена высказываниями-репликами (Винокур, 1998: 135). Для диалога типичны содержатель- 
ная и конструктивная связь реплик, включающих вопросы, ответы, пояснения, добавления, возражения и пр.

В связи с этим пониманием представляется необходимым уточнить ряд моментов. Во-первых, диалог - это не просто взаимодействие (взаимоотношение) культур, а речевое взаимодействие культур. Во-вторых, диалог культур не тождественен межкультурной коммуникации, поскольку последняя может осуществляться неречевыми знаковыми средствами, например, посредством горлового пения, мимики или танца. В-третьих, диалог культур отличен и от межкультурного общения, поскольку последнее включает не только информационный обмен, но и обмен на чувственно-эмоциональном уровне (Leeds-Hurwitz, 2015: 860). Таким образом, о диалоге культур следует говорить только тогда, когда осуществляется содержательный и конструктивный речевой информационный обмен.

Категориальное содержание понятия диалога учитывал М. М. Бахтин. В частности, он обращал внимание на его вопросно-ответное содержание: «Мы ставим чужой культуре новые вопросы, каких она сама себе не ставила, мы ищем в ней ответа на эти наши вопросы, и чужая культура отвечает нам, открывая перед нами новые свои стороны, новые смысловые глубины» (Бахтин, 1979: 335). Таким образом, он указывал на необходимость постановки культурно ориентированных вопросов. При отсутствии таких вопросов нельзя говорить о существовании подлинного диалога культур.

В более общем плане, кроме вопросно-ответного формата диалога культур, важно учитывать наличие способности к диалогу. Для этого культура должна обладать способностью взаимодействовать в речевой, содержательной форме, иначе говоря, быть говорящей, не-молчащей культурой.

Важно также отметить, что «разговор культур» должен осуществляться в режиме именно диалога, а не монолога. Даже обмен монологами может не составлять диалог, если не имеет конструктивного, взаимообогащающего содержания.

Таким образом, «в своем разговоре» культура призвана быть субъектно-ориентированной. Ее должна интересовать и привлекать субъектность чужой культуры в ее самоценности, значимость специфических для нее вопросов и возможный информационный вклад в разрешение вопросов, поставленных собственной культурой.

\section{Урянхайский и другие вопросы тувинской культуры}

В качестве примера культурно значимого вопрошания в отношении тувинской культуры можно рассматривать урянхайский вопрос (Моллеров, Март-оол, 2013; Василенко, 2015; Кузьмин, 2018). Это условное, принятое в дипломатии и исторической литературе обозначение комплекса международных противоречий XVII - начала XX веков, выразившихся в споре России, Китая и Монголии о территориальной принадлежности Урянхайского края, а также в отношении возможности государственного самоопределения тувинского народа.

Урянхайский вопрос появился в рамках решения пограничного вопроса, возникшего между Российской империей и империей Цин. Следовательно, это вопрос не относится к категории вопросов, поставленных собственно в тувинской культуре. Но в поисках того или иного варианта его решения соперничающие стороны обращались к тувинской элите, различные фракции которой по соображениям предпочтений хозяйственной выгоды, этнического происхождения, религиозной и языковой общности или исторической перспективы давали разные ответы.

Вовлечение в диалог содействовало становлению субъектности тувинского народа. Это способствовало решению урянхайского вопроса в его первоначальной постановке путем образования Тувинской Народной Республики, которая в период с 1921 по 1926 годы официально называлась Танну́Ту́ва. Поэтому оправданным представляется говорить о тувинском варианте решения этого вопроса (Самдан, 2019).

Разрешение и снятие урянхайского вопроса выдвинуло на повестку дня так называемый тувинский вопрос. Он состоял в серии аргументированных обращений руководства Тувинской Народной Республики к правительству СССР с просьбами о присоединении (Отрощенко, 2017). В конечном счете этот вопрос был также разрешен - вхождением Тувы в 1944 г. в состав СССР (Хомушку, 2002; Отрощенко, 2017).

Распад Советского Союза в 1991 г. не прошел бесследно для Тувы. В этот период здесь проходили многочисленные дискуссии о перспективах развития республики, в том числе о ее политическом статусе. Главный тувинский вопрос начала 1990-х годов можно обозначить как вопрос тувинского 
суверенитета. В конституции республики 1993 г. предусматривалась возможность выхода из состава России, и ученые всерьез обсуждали перспективы такого сценария (Балакина, Анайбан, 1995: 121-122).

Какой же вопрос сейчас больше всего волнует политиков и тувинскую общественность? В обобщающей мнение экспертов на эту тему публикации с красноречивым названием «Тувинский вопрос номер один» Глава республики Ш. В. Кара-оол таковым предлагает считать подготовку плана социально-экономического развития республики до 2025 года ${ }^{1}$. Понятно, что это чисто управленческая процедура. Более конкретно, речь идет, прежде всего, о создании трансграничного транспортного «меридиана» (транспортного коридора), включающего строительство железной дороги Курагино Кызыл и последующего ее продолжения в Монголию и Китай. Этот проект, как предполагается, выведет экономику Тувы из депрессии.

В предложенной интерпретации данный вопрос можно считать вариацией другого вопроса «Возможна ли модернизация Тувы?» (Ламажаа, 2011: 219). Он имеет социокультурное измерение, если учесть лимитрофное положение Тувы на пограничье российской и китайской цивилизаций. Как показывает международный опыт, модернизация в таком случае блокируется из-за геополитической незаинтересованности в этом великих цивилизаций. Поэтому временный, паллиативный выход Ч. Ламажаа видит в персональной модернизации тувинцев.

Впрочем, далеко не очевидно, что это основной вопрос тувинской культуры - социокультурный эквивалент, например, традиционных вопросов русской культуры «Кто виноват?» и «Что делать?» Поэтому исследования по выявлению основных вопросов тувинской культуры не могут ограничиваться упомянутыми выше и должны быть, по нашему мнению, продолжены.

\section{Открытость к диалогу}

Создание упомянутого выше трансграничного транспортного коридора обсуждается уже более десятилетия и вызывает определенные опасения у части населения Тувы (Кан, 2010; Бегзи, 2011). В некоторой степени это объясняется исторически сложившейся относительной закрытостью тувинского общества.

Прежде всего, Тува изолирована транспортно-географически. Кроме того, жесткую политику тотальной изоляции населения Урянхайского края в свое время проводила империя Цин. Потом ситуация изменилась. Переориентация Тувы на СССР в определенной мере открыла общество для диалога с русской культурой. Но в составе советского государства общая изолированность также сохранялась. Во-первых, сам Советский Союз был в целом закрытым обществом. Во-вторых, поскольку республика относилась к приграничным территориям, доступ в нее иностранцев был закрыт. Да и применительно к современности констатируется, что «для этнической культуры постсоветского этапа истории Тувы характерна замкнутость в ценностном отношении на себе самой» (Karelina, 2018: 226).

С точки зрения типологии культур важно учитывать наличие расположенности культур к диалогу, то, «насколько они открыты для других» (Тетдоева, 2010: 189). Очевидно, что тувинская культура относится к категории сравнительно закрытых культур. Это затрудняет организацию межкультурного диалога, так как открытость признается важнейшим его условием. Что же предпринять в этих условиях?

Выше уже говорилось, что ЮНЕСКО ориентирует на выявление у культур общих элементов и совместных целей. Предпосылкой такого выявления выступает уважительное и заинтересованное отношение к собственной культуре, ее более глубокое познание. В известной смысле, требуется своего рода тувинофильство (тувинское почвенничество) как культурное движение. Более глубокое постижение основ собственной культуры способствует формированию духовных ресурсов, позволяющих оказывать помощь другим культурам и активизировать диалог с ними.

Ю. М. Лотман замечал, что необходимым условием диалога между культурами является взаимная заинтересованность его участников, взаимное влечение - вплоть до взаимной «любви» (Лотман, 2010: 269). Говоря о тувинофильстве, мы фактически и выделяем феномен такой любви.

Напомним, что российскому славянофильству предшествовали другие, более ранние увлечения грекофильство, латинофильство, полонофильство и т. д. К сожалению, нельзя сказать, что эти увлечения были взаимными и диалог этнокультур действительно существовал.

1 Тувинский вопрос номер один [Электронный ресурс] // Клуб регионов: сетевое издание. 2019. 25 июля. URL: http://club-rf.ru/17/detail/3315 (дата обращения: 26.09.2020). 
В тувинской истории в качестве подобных влиятельных настроений выделяются монголофильство и русофильство (Отрощенко, 2020). Отмечаются симпатии к китайской и тибетской культурам. Среди тувинцев очень высок уровень симпатии к японцам. Это настроение, по результатам наших массовых этносоциальных исследований, проведенных в Туве в 2002-2003 годах, отметили 60\% респондентов (Попков, Тюгашев, Костюк, 2006: 29). В настоящее время среди тувинцев популярна корейская культура, что в значительной степени определяется целенаправленной политикой Южной Кореи по ее пропаганде.

В целом можно говорить о симпатии тувинцев к родственным и близким по различным линиям азиатским культурам. Но предпосылки для диалога, как мы видим, имеются в отношении культур только некоторых народов Азии.

\section{Культуры говорящие и культуры молчащие}

Использованное выше различение открытых и закрытых культур (обществ), восходящее к идеям А. Бергсона (обзор этой традиции см.: Gontier, 2015), ориентируется на методологическую возможность отнесения тувинской культуры к тем или иным типам культуры. Типологии культуры конструируются по самым разным основаниям (Chanchani, Shantapriyan, 2009; Коломиец, 2012). Но конечный смысл типологизации культур заключается в определении их идентичности, позволяющей затем определить подходящие для них стратегии развития (Косарская, 2015). Применительно к тувинской культуре предприняты только первые попытки ее идентификации на базе некоторых известных типологий (Ламажаa, 2011: 244; Тюгашев, Попков, 2017; Попков, Тюгашев, 2019). Поэтому представляют интерес типологии культур, значимые в контексте проблемы диалога.

Так, в связи с трактовкой диалога как разговора естественным и даже избыточным кажется выделение «говорящих» культур (Головнев, 1995). Но все ли культуры способны к разговору? В связи с многочисленными исследованиями феномена молчания в различных этнокультурах представляет интерес выделение «молчащих» культур (Скиперских, 2018). Исходя из этого, возможно различение культур молчащих и культур говорящих. Внешне это различение опознается по стилю речевого общения, сравнительной ценности шума и тишины. Например, английская, русская, японская культуры идентифицируются как культуры молчания. Как шумные народы воспринимаются греки, итальянцы, китайцы, корейцы, французы и др. Более молчаливы культуры народов Севера.

Тувинская культура, по-видимому, является культурой молчания. В особенной степени эта характеристика относится к тувинцам-тоджинцам. Так, А. Ч. Чадамба делится впечатлением: «Тувинцытоджинцы - молчаливые, а если говорят, то очень тихо. Не умеют жаловаться, роптать, хотя проблем у них хватает» ${ }^{.}$

Реабилитируя молчание культур коренных малочисленных народов Севера, А. В. Головнев писал: «Итак, одно из главных для меня самого открытий состоит в том, что культура не говорит ничего лишнего. Другое, не менее очевидное: если ты хочешь услышать культуру - слушай, не мучай ее вопросами, не торопи с ответами, отпусти ее, дай ей увлечься собой, заслушаться себя, залюбоваться собой» (Головнев, 1995: 30). Таким образом, даже молчаливая культура, по его мнению, через некоторое время может заговорить, вступить в диалог. И об этом также упоминает Ч. Чадамба: «Но разговорить немногословных горных таёжников можно - нужны лишь уважение, терпение и искренняя заинтересованность»².

Ю. М. Лотман полагал, что молчание культуры может объясняться тем, что она находится в стадии приема, рецепции информации. Это своего рода пауза в диалоге, позволяющая осмыслить услышанное и дать ответ. Так, например, Италия в раннем средневековье выступала как «получатель» светских текстов. Но затем она стала, по его оценке, «настоящим вулканом, извергающим самые разнообразные тексты, заполняющие культурную ойкумену Запада» (Лотман, 2010: 271).

Любопытно, что диалог культур описывается как носящий ненаправленный, не дуальный характер, а круговой. Слушать можно одну или несколько культур, а отвечать - всем, кто прислушивается. Такой паттерн диалога культур более точно соответствует его изначальному пониманию как разговора, беседы многих участников.

${ }^{1}$ Цит. по: Антуфьева Н. Вслед за тувинскими оленями отправились кызыльские слушатели школы межэтнической журналистики [Электронный ресурс] // Союз журналистов России: сетевое издание. 2018. 16 мapтa. URL: https:// ruj.ru/news/regions-news/vsled-za-tuvinskimi-olenyami-otpravilis-kyzylskie-slushateli-shkoly-mezhetnicheskoyzhurnalistiki-bl-8451 (дата обращения: 20.09.2020).

${ }^{2}$ Цит. по: там же. 


\section{Диалоговые и монологовые культуры}

В коммуникативной ситуации ненаправленного диалога - не имеющего конкретного адресата культура выступает с монологом. Поэтому она может восприниматься в качестве монологической культуры, не ориентированной на диалог.

В мировой истории предложено различать монологичные и диалогичные культуры (Тетдоева, 2010: 188). Можно согласиться с наблюдением о том, что монолог - наиболее ранняя, восходящая к этноцентризму, стратегия межкультурной коммуникации (Яркова, 2012: 64). Он может оставаться превалирующей стратегией в рамках любого моноцентризма. Поэтому в качестве монологичных идентифицируются монотеистические культуры, западная культура в целом, культуры тоталитарных и авторитарных обществ. Диалог в этих культурах фактически может являться обменом монологами, безадресными и не требующими ответа, то есть квазидиалогом.

Вместе с тем довольно рано, особенно в художественной литературе, в качестве культурной нормы формируются диалоговые формы. Например, в шумеро-аккадской литературе был широко представлен жанр диалога-спора о превосходстве, который велся не только между людьми, но и между различными существами, предметами и явлениями природы (Емельянов, 2012: 76).

Не претендуя на тотальную достоверность, выскажем предположение, что тувинская культура в силу своей патриархальности и авторитарности по преимуществу монологична. В художественной литературе это проявляется в активном обращении к жанрам восхвалений, наказа, плача, причитаний, представляющих собой монологическую речь героя (Дампилова, 2016: 45). Но наряду с этим следует учитывать диалогическую традицию буддизма, актуализация которой позволила бы ввести в культурную норму диспуты, дискуссии, дебаты по различным темам.

\section{Заключение}

Большая часть того, что говорилось выше о тувинской культуре, касалось культуры традиционной. Постепенно формируясь в качестве устойчивой и достаточно оптимальной адаптивной системы духовных представлений и реальных практик, она является продуктом взаимного приспособления сообщества к конкретным природно-географическим и геополитическим условиям. Именно специфическое пространственное положение и сложности исторического развития Тувы определили особенности тувинской культуры. По итогам проведенного сравнительного анализа традиционной тувинской культуры в горизонте типологии культур можно сделать следующие выводы: по критерию открытости к диалогу она относится к категории сравнительно закрытых культур; по критерию избирательности в диалоге тувинцев можно охарактеризовать как преимущественно азиатско-ориентированных; в рамках сопоставления культур «говорящих» и «молчащих» тувинская культура больше соответствует культуре молчания; в горизонте диалоговых и монологовых культур ее можно оценить как в большей степени монологичную.

Современная эпоха, характеризующаяся включением локальных и региональных сообществ в широкие глобальные связи, а также цифровизацией публичной и повседневной жизни, создает невиданные ранее возможности для переформатирования и самой культуры, и ее диалоговых возможностей. В этих условиях одной из важных научных проблем становятся осмысление причудливого переплетения траекторий традиционной и современной культур в процессе интенсифицирующихся межкультурных взаимодействий. Пандемия коронавируса существенно снизила, надо надеяться, что временно, возможности реальных контактов, но одновременно породила потребность и создала новые формы контактов виртуальных, тем самым усложнив и запутав проблемную ситуацию в сфере диалога культур и актуализировав задачу специального исследования на эту тему.

\section{СПИСОК ЛИТЕРАТУРЫ}

Адыгбай, Ч. О. (2012) Диалог тувинской и западной культур (на примере жизни ученого Ондара Дарыма) [Электронный ресурс] // Новые исследования Тувы. № 2. URL: https://nit.tuva.asia/nit/article/view/316/ 627 (дата обращения: 06.10.2020).

Балакина, Г. Ф., Анайбан, 3. В. (1995) Современная Тува: социокультурные и этнические процессы. Новосибирск : Наука. 137 с.

Бахтин, М. М. (1979) Эстетика словесного творчества. М. : Искусство. 424 с. 
Бегзи, А. Д. (2011) Будет ли экономика Сибири прирастать Тувой? «Новая индустриализация» Сибири и проблемы экономического развития Тувы [Электронный ресурс] // Новые исследования Тувы. № 1. URL: https://nit. tuva.asia/nit/article/view/438 (дата обращения: 06.10.2020).

Библер, В. С., Ахутин, А. В. (2010) Диалог культур // Новая философская энциклопедия : в 4 т. / научно.-ред. совет: В. С. Стёпин, А. А. Гусейнов, Г. Ю. Семигин, А. П. Огурцов. 2-е изд., испр. и допол. М. : Мысль. Т. 1. 744 с. С. $659-661$.

Василенко, В. А. (2015) «Урянхайский вопрос» в международной политике России, Монголии, Китая (первая четверть XX века): источниковедение и историография проблемы // Россия и Монголия в первой половине XX века: концептуальные вопросы российско-монгольских отношений (дипломатия, экономика, наука). УланБатор ; Иркутск : Изд-во БГУ. 416 с. С. 99-114.

Винокур, Т. Г. (1998) Диалогическая речь // Языкознание. Большой энциклопедический словарь / гл. ред. В. Н. Ярцева. М. : Большая Российская энциклопедия. 685 с. С. 135.

Головнев, А. В. (1995) Говорящие культуры: традиции самодийцев и угров. Екатеринбург : УрО РАН. 606 с.

Дампилова, Л. С. (2016) Тюркомонгольские истоки в современной поэзии народов Сибири // Mongolica-XVI. СПб. : Петербургское востоковедение. 104 с. С. 44-50.

Емельянов, В. В. (2012) Шумерская литература // Литературы стран Азии и Африки. Начальный период развития / отв. ред. В. В. Емельянов. СПб. : ИПК «НП-Принт». 348 с. С. 31-108.

Жбанков, М. Р. (2001) Диалог культур // Всемирная энциклопедия: Философия / гл. ред. А. А. Грицанов. М. : АСТ ; Минск : Харвест, Современный литератор. 1312 с. С. 308-309.

Кан, В. С. (2010) Чего ждут от строительства железной дороги и освоения месторождений жители Тувы (по материалам социологических исследований 2008-2010 гг.) [Электронный ресурс] // Новые исследования Тувы. № 4. URL: https://nit.tuva.asia/nit/article/view/477 (дата обращения: 06.10.2020).

Коломиец, Н. В. (2012) Современный концепт типологии культуры // Государственное и муниципальное управление. № 4. С. 7-12.

Косарская, Е. С. (2015) Типология культуры как символическая борьба за самоидентичность // Культура и образование. № 4. С. 42-48.

Кузьмин, С. Л. (2018) Урянхайский вопрос и монголо-тувинские отношения в начале XX в. // Oriental Studies. № 3. C. 2-14. DOI: https:// www.doi.org/10.22162/2619-0990-2018-37-3-2-14

Ламажаа, Ч. К. (2011) Тува между прошлым и будущим. 2-е изд. СПб. : Алетейя. 368 с.

Ламажаа, Ч. К. (2018) Национальный характер тувинцев. М. ; СПб. : Нестор-История. 240 с.

Ларченко, С. Г., Еремин, С. Н. (1991) Межкультурные взаимодействия в историческом процессе. Новосибирск : Наука. 174 с.

Лотман, Ю. М. (2010) Семиосфера. СПб. : Искусство - СПБ. 704 с.

Маадыр, М. С. (2018) США и Тувинская Народная Республика: вопросы книгообмена (по документам Государственного архива Республики Тыва) // Библиосфера. № 2. C. 24-27. DOI: https://www.doi.org/10.20913/18153186-2018-2-24-27

Моллеров, Н. М., Март-оол, В. Д. (2013) «Урянхайский вопрос» в политической истории России: возникновение и долговременная актуальность. Абакан : Журналист. 244 с.

Монгуш, М. В. (2008) Тува: диалог культур в прошлом и настоящем (на материалах книги Отто Менхен-Хельфена «Путешествие в азиатскую Туву») // Современные проблемы сервиса и туризма. № 4. С. 10-26.

Орнатская, Л. А. (2014) Межкультурный диалог: проблемы и перспективы исследования // Вестник Санкт-Петербургского университета Сер. 6. Вып. 1. С. 48-60.

Отрощенко, И. В. (2017) Вхождение Тувы в состав СССР: альтернативные мнения // Новые исследования Тувы. № 4. C. 36-76. DOI: https:// www.doi.org/10.25178/nit.2017.4.3

Отрощенко, И. В. (2020) «Монголофильство» политической элиты Тувинской Народной Республики // Новые исследования Тувы. № 3. С. 35-48. DOI: www.doi.org/10.25178/nit.2020.3.3

Попков, Ю. В., Тюгашев, Е. А. (2019) Пространственный образ Тувы в объективе социокультурной феноменологии // Новые исследования Тувы. № 3. С. 4-14. DOI: https://www.doi.org/10.25178/nit.2019.3.1

Попков, Ю. В., Тюгашев, Е. А., Костюк, В. Г. (2006) Этносоциальные процессы в современной Евразии: история и современность // Этносоциальные процессы в Сибири / под ред. Ю. В. Попкова. Новосибирск : Сибирское Научное Издательство. 230 с. Вып. 7. С. 12-31.

Попов, Е. Н. (2005) Сущностные характеристики диалога в современной философии // Вестник Якутского государственного университета. № 1. С. 69-74.

Самдан, А. А. (2019) Российский и тувинский варианты решения «урянхайского вопроса» (1911-1916 гг.) // Ученые записки. Выпуск XXV / Тувинский институт гуманитарных и прикладных социально-экономических исследований при Правительстве Республики Тыва / отв. ред. Б. А. Донгак. Кызыл : Типография МБОУ КЦО «Аныяк». 452 с. С. 34-55. 
Скиперских, А. В. (2018) Официальное и неофициальное искусство в «молчащей» культуре: взгляд нонконформистов // Международный журнал исследований культуры. № 1. С. 189-197.

Тетдоева, С. А. (2010) Диалог как форма коммуникации в сфере межкультурных контактов // Труды СанктПетербургского государственного университета культуры и искусств. Т. 190. С. 185-190.

Тульчинский, г. Л. (2015) Философия как парадигма межкультурного диалога // Философские науки. № 11. C. $148-154$.

Тхагапсоев, Х. Г., Астафьева, О. Н., Докучаев, И. И., Леонов, И. В. (2020) Информационно-семиотическая теория культуры. СПб. : Астерион. 208 с.

Тюгашев, Е. А. (2019) О. Шпенглер и социокультурный подход // Тезаурусы и проблемы культуры / отв. ред. В. А. Луков. М.: Московский гуманитарный университет. 401 с. С. 272-281.

Тюгашев, Е. А., Попков, Ю. В. (2017) Менталитет тувинцев в горизонте социокультурной феноменологии Питирима Сорокина // Новые исследования Тувы. № 3. С. 4-17. DOI: https://www.doi.org/10.25178/nit.2017.3.1

Хомушку, Ю. Ч. (2002) Процессы сближения и вхождения Тувинской Народной Республики в состав СССР: 20-40-е годы ХХ в. : автореф. дис. ... к. ист. н. М. 18 с.

Яркова, Е. Н. (2012) Стратегии межкультурной коммуникации: От монолога к диалогу // Вестник Ишимского педагогического института им. П. П. Ершова. № 1. С. 64-70.

Aman, R. (2012) The EU and the Recycling of Colonialism: Formation of Europeans Through Intercultural Dialogue // Educational Philosophy and Theory. No. 44 (9). P. 1010-1023.

Chanchani, Sh., Shantapriyan, P. (2009) Typologies of Culture // SSRN Electronic Journal. 30 July. DOI: http://dx.doi. org/10.2139/ssrn.1441609

Cliche, D., Wiesand, A. (2009) Achieving Intercultural Dialogue through the Arts and Culture? Concepts Policies Programmes Practices // D'Art Topics in Arts Policy. No. 39. P. 5-46.

Gontier, T. (2015) Open and Closed Societies: Voegelin as a Reader of Bergson // Politics, Religion and Ideology, issue 1. P. 23-38.

Igbino, J. (2011) Intercultural Dialogue: cultural dialogues of equals or cultural dialogues of unequals? // Policy Futures in Education. Vol. 9. No. 1. P. 57-65.

Karelina, E. K. (2018) The Problematic Aspects of Cultural Policy in Modern Tuva // Journal of Siberian Federal University. Humanities \& Social Sciences. No. 11. P. 218-226.

Leeds-Hurwitz, W. (2014) Intercultural dialogue [Электронный ресурс] // Key Concepts in Intercultural Dialogue. No. 1. URL: https://centerforinterculturaldialogue.files.wordpress.com/2014/02/key-concept-intercultural-dialogue1.pdf (дата обращения: 06.10.2020).

Leeds-Hurwitz, W. (2015) Intercultural dialogue // International encyclopedia of language and social interaction / K. Tracy, C. Ilie \& T. Sandel (Eds.). Boston : John Wiley \& Sons. Vol. 2, P. 860-868. DOI: https://www.doi. org/10.1002/9781118611463/wbielsi061

Дата поступления: 10.10.2020 2.

\section{REFERENCES}

Adygbai, Ch. O. (2012) Dialog tuvinskoi i zapadnoi kultur (na primere zhizni uchenogo Ondara Daryma) [Dialogue of Tuvan and Western cultures, as exemplified by the scientist Ondar Daryma's life]. New Research of Tuva, no. 2, [online] Available at: https://nit.tuva.asia/nit/article/view/316/ 627 (access date: 06.10.2020). (In Russ.).

Balakina, G. F. and Anaiban Z. V. (1995) Sovremennaia Tuva: sotsiokul'turnye i etnicheskie protsessy [Contemporary Tuva: socio-cultural and ethnic processes]. Novosibirsk, Nauka, Sib. izd. firma. 137 p. (In Russ.).

Bakhtin, M. M. (1979) Estetika slovesnogo tvorchestva [Aesthetics of verbal art]. Moscow, Iskusstvo. 424 p. (In Russ.).

Begzi, A. D. (2011) Budet li ekonomika Sibiri prirastat Tuvoi? «Novaia industrializatsiia» Sibiri i problemy ekonomicheskogo razvitiia Tuvy [Will the economy of Siberia grow by Tuva? «New industrialization» of Siberia and problems of Tuva's economic development]. New Research of Tuva, no. 1 [online] Available at: https://nit.tuva.asia/nit/article/ view/438 (access date: 06.10.2020). (In Russ.).

Bibler, V. S. and Akhutin, A. V. (2010) Dialog kultur [Dialogue of cultures]. In: Novaia filosofskaia entsiklopediia [New Encyclopedia of Philosophy]: in 4 vols. Moscow, Mysl. Vol. 1. 744 p. Pp. 659-661. (In Russ.).

Vasilenko, V. A. (2015) «Uriankhaiskii vopros» V mezhdunarodnoi politike Rossii, Mongolii, Kitaia (pervaia chetvert XX veka): istochnikovedenie i istoriografiia problemy [The Uriankhai issue in the international politics of Russia, Mongolia, and China in the first quarter of the twentieth century: source studies and historiography of the problem]. In: Rossiia $i$ Mongoliia v pervoi polovine XX veka: kontseptualnye voprosy rossiisko-mongolskikh otnoshenii (diplomatiia, ekonomika, nauka) [Russia and Mongolia in the first half of the twentieth century: conceptual issues of Russian-Mongolian relations (diplomacy, Economics, science)]. Ulan-Bator, Irkutsk, Izd-vo BGU. 416 p. Pp. 99-114. (In Russ.). 
Vinokur, T. G. (1998) Dialogicheskaia rech [Dialogic speech]. In: Yazykoznanie. Bolshoi entsiklopedicheskii slovar [Linguistics: A Large Encyclopaedic Dictionary]. Ed. by V. N. Yartseva. Moscow, Bolshaia Rossiiskaia entsiklopediia. 685 p. P. 135. (In Russ.).

Golovnev, A. V. (1995) Govoriashhie kultury: traditsii samodiitsev i ugrov [Talking cultures: Samoyed and Ugrian traditions]. Ekaterinburg, UrO RAN. 606 p. (In Russ.).

Dampilova, L. S. (2016) Tiurkomongolskie istoki v sovremennoi poiezii narodov Sibiri [Turkic and Mongolian sources of the modern poetry of the peoples of Siberia]. In: Mongolica-XVI [Mongolica-XVI]. St. Petersburg, Peterburgskoe vostokovedenie. 104 p. Pp. 44-50. (In Russ.).

Emelianov, V. V. (2012) Shumerskaia literatura [Sumerian literature]. In: Literatury stran Azii i Afriki. Nachalnyi period razvitiia [Asian and African Literatures. The earliest period]. Ed. by V. V. Emelianov. St. Petersburg, IPK «NP-Print». 348 p. Pp. 31-108. (In Russ.).

Zhbankov, M. R. (2001) Dialog kultur [Dialogue of cultures]. In: Vsemirnaia entsiklopediia: Filosofiia [World entsyclopedia: Philosophy]. Ed. by A. A. Gritsanov. Moscow, ACT, Minsk, Harvest, Sovremennyi literator. 1312 p. Pp. 308-309. (In Russ.).

Kan, V. S. (2010) Chego zhdut ot stroitel'stva zheleznoi dorogi i osvoeniia mestorozhdenii zhiteli Tuvy (po materialam sotsiologicheskikh issledovanii 2008-2010 gg.) [What the residents of Tuva expect from the construction of the railway and the development of minerals (based on the materials of sociological research in 2008-2010)]. New Research of Tuva, no. 4, [online] Available at: https://nit.tuva.asia/nit/article/view/477 (access date: 06.10.2020). (In Russ.).

Kolomiets, N. V. (2012) Sovremennyi kontsept tipologii kultury [The contemporary concept of typology of culture]. Gosudarstvennoye i munitsipalnoye upravlenie , no. 4, pp. 7-12. (In Russ.).

Kosarskaya, E. S. (2015) Tipologiia kul'tury kak simvolicheskaia borba za samoidentichnost [Typology of culture as a symbolic struggle for self-identity]. Culture and education, no. 4, pp 42-48. (In Russ.).

Kuzmin, S. (2018) Urianhaiskii vopros i mongolo-tuvinskie otnosheniia v nachale XX v. [The Uriankhai issue and Mongolia-Tuva relations in early 20th Century]. Oriental Studies, no. 3, pp. 2-14. (In Russ.). DOI: https://www.doi. org/10.22162/2619-0990-2018-37-3-2-14

Lamazhaa, Ch.K.(2011) Tuva mezhdu proshlym i budushchim [Tuva between the past and the future].2nd ed. St. Petersburg, Aleteiia. 368 p. (In Russ.)

Lamazhaa, Ch. K. (2018) Natsionalnyi kharakter tuvintsev [The national character of Tuvans]. Moscow, St. Petersburg, Nestor-Istoriia. 240 p. (In Russ.).

Larchenko, S. G. and Eremin, S. N. (1991) Mezhkulturnye vzaimodeistviia v istoricheskom protsesse [Intercultural interactions in the historical process]. Novosibirsk, Nauka. 174 p. (In Russ.).

Lotman, Yu. M. (2010) Semiosfera [Semiosphere]. St. Petersburg, Iskusstvo - SPb. 704 p. (In Russ.).

Maadyr, M. S. (2018) SShA i Tuvinskaia Narodnaia Respublika: voprosy knigoobmena [The USA and Tuvan People’s Republic: issues of book exchange (from the documents at the State Archives of the Republic of Tuva)]. Bibliosfera [Bibliosphere], no. 2, pp. 24-27. (In Russ.). DOI: https://www.doi.org/10.20913/1815-3186-2018-2-24-27

Molerov, N. M. and Mart-ool, V. D. (2013) «Uriankhaiskii vopros»v politicheskoi istorii Rossii: vozniknovenie $i$ dolgovremennaia aktual'nost' [The "Uriankhai issue" in the political history of Russia, its emergence and long-term relevance]. Abakan, Kooperativ «Zhurnalist». 244 p. (In Russ.).

Mongush, M. V. (2008) Tuva: dialog kultur v proshlom i nastoiashhem [Tuva: Dialogue of cultures in the past and present]. Sovremennye problemy servisa i turizma [Contemporary problems of service and tourism], no 4, pp. 10-26. (In Russ.).

Ornatskaia, L. A. (2014) Mezhkulturnyi dialog: problemy i perspektivy issledovaniia [Intercultural dialogue: problems and prospects of studies]. Vestnik of St.-Petersburg University, ser. 6, issue 1, pp. 48-60. (In Russ.).

Otroshhenko, I. V. (2017) Vhozhdenie Tuvy v sostav SSSR: alternativnye mneniia [Tuva's accession to the USSR: Alternative opinions]. New Research of Tuva, no. 4, pp. 36-74. (In Russ.). DOI: https:// www.doi.org/10.25178/nit.2017.4.3

Otroshhenko, I. V. (2020) «Mongolofilstvo» politicheskoi ielity Tuvinskoi Narodnoi Respubliki ["Mongolophilia” of the political elite in the Tuvan People’s Republic]. New Research of Tuva, no. 3, pp. 35-48. (In Russ.). DOI: https://www.doi. org/10.25178/nit.2020.3.3.

Popkov, Yu. V. and Tyugashev, E. A. (2019) Prostranstvennyi obraz Tuvy v obiektive sotsiokulturnoi fenomenologii [The spatial image of Tuva in the focus of sociocultural phenomenology]. New Research of Tuva, no. 3, pp. 4-14. (In Russ.). DOI: www.doi.org/10.25178/nit.2019.3.1

Popkov, Yu. V., Tyugashev, E. A. and Kostyuk, V. G. (2006) Etnosocialnye processy v sovremennoi Evrazii: istoriia i sovremennost [Ethnosocial processes in modern Eurasia: history and modernity]. In: Etnosotsialnye processy $v$ Sibiri [Ethnosocial processes in Siberia]. Ed. by Yu. V. Popkov. Novosibirsk, Sibirskoe Nauchnoe Izdatelstvo. 230 p. Vol. 7. Pp. $12-31$. (In Russ.).

Popov, E. N. (2005) Suschnostnye harakteristiki dialoga v sovremennoi filosofii [The nature of dialogue contemporary philosophy]. Bulletin of the Yakut state University, vol. 1, pp. 69-74. (In Russ.). 
Samdan, A. A. O. (2019) Rossiiskii i tuvinskii varianty resheniia «urianhaiskogo voprosa» (1911-1916 gg.) [Russian and Tuvan options for resolving the uryanhay issue (1911-1916)]. In: Uchenye zapiski. Tuvinskii institut gumanitarnykh i prikladnykh sotsialno-ekonomicheskikh issledovanii pri Pravitel'stve Respubliki Tyva. Vol XXV. Ed. by B. A. Dongak. Kyzyl, Typography MBOU SCB “Aniak”. 452 p. Pp. 34-55. (In Russ.).

Skiperskikh, A. V. (2018) Ofitsialnoe i neofitsialnoe iskusstvo v «molchashchei» kulture: vzgliad nonkonformistov [Official and unofficial art in the «silent» culture: A nonconformist view]. International journal of cultural studies, no. 1, pp. 189-197. (In Russ.).

Tetdoeva, S. A. (2010) Dialog kak forma kommunikatsii v sfere mezhkulturnykh kontaktov [Dialogue as a form of communication in the field of intercultural contacts]. Proceedings of the St. Petersburg State University of culture and arts, vol. 190, pp. 185-190. (In Russ.).

Tulchinskii, G. L. (2015) Filosofiia kak paradigma mezhkulturnogo dialoga [Philosophy as a paradigm of intercultural dialogue]. Russian Journal of Philosophical Sciences, no. 11, pp. 148-154. (In Russ.).

Thagapsoev, H. G., Astaf'eva, O. N., Dokuchaev, I. I., and Leonov, I. V. (2020) Informatsionno-semioticheskaia teoriia kultury [Information and semiotic theory of culture]. St. Petersburg, Asterion. 208 c. (In Russ.).

Tyugashev, E. A. (2019) O. Shpengler i sociokulturnyi podhod [O. Spengler and the sociocultural approach]. In: Tezaurusy i problemy kultury [Thesauri and the problem of culture]. Ed. by Val. A. Lukov. Moscow, Moscow University for the Humanities Publ. 401 p. Pp. 272-281. (In Russ.).

Tyugashev, E. A. and Popkov, Yu. V. (2017) Mentalitet tuvintsev v gorizonte sotsiokulturnoi fenomenologii Pitirima Sorokina [Mindset of Tuvans in terms of Pitirim Sorokin's cultural phenomenology]. New Research of Tuva, no. 3, pp. 4-17. (In Russ.). DOI: https://doi.org/10.25178/nit.2017.3.1

Khomushku, Yu. Ch. (2002) Protsessy sblizheniia i vkhozhdeniia Tuvinskoi Narodnoi Respubliki v sostav SSSR: 20-40-e gody XX v. [Process of rapprochement and accession of the Tuvan People's Republic in the USSR: 1920s-1940s]: Abstract of Diss.... Candidate of History. Moscow. 18 p. (In Russ.).

Yarkova, E. N. (2012) Strategii mezhkulturnoi kommunikacii: Ot monologa k dialogu [Intercultural communication strategies: From monologue to dialogue]. Bulletin of the Ishim Pedagogical Institute named after P. P. Yershov, no 1, pp. 64-70. (In Russ.).

Aman, R. (2012) The EU and the Recycling of Colonialism: Formation of Europeans Through Intercultural Dialogue. Educational Philosophy and Theory, no. 44 (9), pp. 1010-1023.

Chanchani, Sh. and Shantapriyan, P. (2009). Typologies of Culture. SSRN Electronic Journal. 30 July. DOI: http://dx.doi. org/10.2139/ssrn.1441609

Cliche, D. and Wiesand, A. (2009) Achieving Intercultural Dialogue through the Arts and Culture? Concepts Policies Programmes Practices. D'Art Topics in Arts Policy, no. 39, pp. 5-46.

Igbino, J. (2011) Intercultural Dialogue: cultural dialogues of equals or cultural dialogues of unequals? Policy Futures in Education, vol. 9, no. 1, pp. 57-65.

Karelina, E. K. (2018) The Problematic Aspects of Cultural Policy in Modern Tuva. Journal of Siberian Federal University. Humanities \& Social Sciences, no. 11, pp. 218-226.

Leeds-Hurwitz, W. (2014) Intercultural dialogue. Key Concepts in Intercultural Dialogue, no. 1 [online] Available at: https://centerforinterculturaldialogue.files.wordpress.com/2014/02/key-concept-intercultural-dialogue1.pdf (access date: 06.10.2020).

Leeds-Hurwitz, W. (2015) Intercultural dialogue. In: International encyclopedia of language and social interaction. Ed. by K. Tracy, C. Ilie and T. Sandel. Boston, John Wiley \& Sons. Vol. 2, Pp. 860-868. DOI: https://www.doi. org/10.1002/9781118611463/wbielsi061

Submission date: 10.10.2020 2. 